\title{
Resenha
}

\section{RESENHA: PAI RICO PAI POBRE}

(KIYASAKI, Robert. Pai rico Pai pobre. 53 ed. São Paulo: Campus, 2002)

Aramis de Albuquerque Farias (1)

Esta obra é uma espécie de autobiografia de Robert Kiyosaki, onde ele relata experiências com seu amigo Mike. Robert conta que era filho de um professor universitário, sem tantas perspectivas financeiras, e que encontra Mike, cujo pai é um homem muito instruído e inteligente. Os pais dos dois amigos são pessoas influentes socialmente, por conta de suas carreiras, embora o pai de Robert sempre com algumas dificuldades financeiras. Os dois acreditam na educação, mas com visões diferentes. Enquanto um referia que: "O amor ao dinheiro é a raiz de todo o mal" o outro comentava exatamente o oposto: "A falta de dinheiro é a raiz de todo o mal".

O autor dá ênfase às recomendações ambíguas: enquanto um dos pais recomendava "Estude arduamente para poder trabalhar em uma boa empresa" o outro ressaltava: "Estude arduamente para comprar uma empresa". E refere que foi refletindo as opiniões diferentes que teve a oportunidade de escolher sua trajetória econômica. No caso, oriunda das informações e conselhos do pai de Mike, a quem se refere como "o pai rico".

Os amigos Robert e Mike estudaram em uma escola pública, onde normalmente estudavam filhos de pessoas ricas, e segundo o autor, foi quando Robert começou a indagar seu pai, como ele (Robert) poderia ficar rico. Seu pai não lhes deu uma explicação convincente. Em seguida, Robert propõe a Mike uma sociedade, de forma a que os dois possam ficar ricos. O primeiro negócio dos dois foi um fiasco. O pai de Robert reconheceu o esforço dos dois jovens e os aconselhou que fossem pedir ajuda sobre, como ficar rico, ao pai de Mike, "o pai rico". O autor conta que foi neste ponto que conheceu os ensinamentos importantes que ele tanto buscava.

Começou a trabalhar e estudar com o pai rico, que lhe ofereceu um emprego em uma de suas lojas.

O pai rico começa então uma série de reflexões sobre a importância de termos objetivos e persistência, e que devemos fazer com que "o dinheiro trabalhe para nós ao invés de trabalharmos para o dinheiro". Também orientou que não importa tanto o quanto se ganha, mas sim o quanto se consegue guardar. E que, para se realizar um grande sonho devemos planejar. E ressalta que uma construção sem planejamento não tende a durar.

O pai rico continua explicando que muitas pessoas se ocupam em TER, não dão muita atenção ao SABER, quando pensam em ficarem ricas. Mas que para chegarem a tal ponto é necessário compreender, por exemplo, a diferença entre o Ativo e o Passivo. O Ativo coloca dinheiro no seu bolso. O Passivo tira dinheiro do seu bolso. E também que o dinheiro só acentua o padrão de fluxo de caixa que está na sua mente. Se seu padrão for gastar tudo o que ganha, o mais provável é que um aumento de dinheiro disponível, apenas resulte em um aumento de despesas.

Que a educação deve consistir, não em saber como ganhar dinheiro, mas em como gasta-lo. Isto é, o que fazer com ele depois de tê-lo ganho?. 
O pai de Mike explica que os ricos compram ativos, que os pobres só tem despesas e que, a classe média compra passivos, pensando que são ativos.

O autor explica que "Se tiver que trabalhar nos negócios, não é negócio" e que ativos são: Ações; Títulos; Fundos Mútuos; Imóveis que geram renda; Promissória, dentre outros.

Ele orienta que se compre ativos que goste. Pois o que você gosta, você tende a cuidar. E também que, em questões financeiras, faz-se necessário o conhecimento do sistema legal, juntamente com a contabilidade, para que se possa adequar os investimentos à menor incidência de impostos. Nesse aspecto a sociedade anônima constitui uma excelente ferramenta. Pois além de proteger os ativos sob um manto de artifícios legais, faz com que os impostos incidam sobre o saldo do faturamento, menos todos os gastos. Enquanto que para uma pessoa física o desconto do imposto dá-se na fonte de sua renda.

$\mathrm{O}$ autor nos ensina que todos temos uma série de recursos internos que podem nos transformar em empreendedores bem sucedidos. E, que isso comumente não ocorre por falta de autoconfiança. Que características como ousadia, coragem, audácia, esperteza e persistência, entre outras, não são eficientemente desenvolvidas pelo sistema educativo que temos. E isso prejudica nossa capacidade de avaliar e assumir riscos, administrando-os em cada oportunidade que nos aparece. Que todos temos uma tendência natural a buscar segurança, o que geralmente não é a melhor escolha para sermos bem sucedidos em nossos empreendimentos.

Os empreendedores encontram oportunidades onde a grande maioria não as vê. Assumem riscos baseando-se em conhecimentos financeiros contábeis e jurídicos capazes de tornarem estes riscos calculáveis e então entrar no "jogo" do mercado para sonhar. Se fracassarem, sabem que isso faz parte da busca do sucesso e usam isso para tornarem-se mais atentos na próxima oportunidade. Dessa forma, vão acumulando ativos ao longo da vida. Pessoas que não desenvolvem esta inteligência financeira, passam o tempo inteiro fazendo contas de como saldar suas dívidas, reclamando do patrão e do governo. Na verdade o que poderia mudar sua situação econômica seria uma mudança de atitude frente às oportunidades, passando da acomodação à ação.

$\mathrm{O}$ autor propõe que um profissional deve se preocupar em aprender, em ampliar seus conhecimentos, independentemente do ramo de negócio que venha escolher. Não devemos trabalhar pensando exclusivamente em um salário melhor ou em um emprego mais estável, porque se nos especializarmos em uma única área, ficaremos dependentes deste mercado, e portanto, vulneráveis profissionalmente.

Devemos desenvolver habilidades e conhecimentos gerais que nos servirão para administrar o nosso negócio. Algumas habilidades como vendas e entendimento de organização, são básicas para que possamos obter sucesso em qualquer atividade. Em resumo, se você aprender a vender bem a sua idéia, independente de qual seja, terá sucesso. Assim, quanto melhor você se comunicar, negociar e administrar, mais sucesso terá. Devemos aprender que também devemos ser eternos alunos e eternos professores, que devemos dar para poder receber.

Outra reflexão importante levantada pelo autor é que, algumas das nossas fragilidades emocionais, também podem gerar dificuldades na aquisição da tão sonhada "riqueza financeira".

São elas: $\mathrm{O}$ medo de encarar o risco; O pessimismo exagerado, influenciando negativamente a si mesmo e aos que possam vir a colaborar conosco; A preguiça de perseguir objetivos mais difíceis de realizar; Os maus hábitos, tal como a procrastinação; a arrogância. O autor reforça ainda que em cada um de nós reside um gênio financeiro, para algumas pessoas este gênio está adormecido, pois nossa cultura nos ensina que o amor ao dinheiro é a raiz de todos os males. Nossa cultura nos ensina a não nos preocuparmos com o futuro financeiro. Devemos definir os "não quero" e os "quero" na vida, ou seja, não quero perder dinheiro, não quero trabalhar a 
vida inteira, não quero ser empregado. Os "não quero", eles criam os "quero". Exemplo: quero ser livre para viajar por todo o mundo e viver o estilo de vida que gosto, quero controlar meu tempo e minha vida.

Por fim, o autor propõe dez passos importantes a seguir, rumo ao sucesso financeiro:

$1^{\circ}$ - Tenha um objetivo, algo motivador. Escolha o que você quer, sem medo dos riscos;

$2^{\circ}$ - Escolha as opções que colocam você mais próximo de seus objetivos.

$3^{\circ}$ - Escolha seus amigos, não somente por sua situação financeira, mas sim, pelo que essa pessoa possa lhe transmitir de ensinamentos e conhecimentos, bons ou ruins. Bons para que você possa fazer o mesmo e ruins para que você nunca os faça.

$4^{\circ}$ - Domine uma fórmula de fazer algo cada vez melhor e mais rápido, isto serve também para ganhar dinheiro.

$5^{\circ}$ - Autodisciplina, ou seja, pague primeiro a si mesmo, mesmo sem dinheiro, pague a si mesmo primeiro, porque a partir daí você usará a cobrança de seus credores como motivação e determinação para conseguir o quer.

$6^{\circ}$ - Pague bem as pessoas que trabalham para você, principalmente aquelas que lhe ajudam a ganhar dinheiro.

$7^{\circ}$ - Sempre que emprestar, solicite de volta, sempre observe o retorno sobre o investimento: são os ativos que você obtém de graça, depois que você recebe seu dinheiro de volta. Isso é inteligência financeira.

$8^{\circ}$ - Ativos compram supérfluos, ou seja, concentre-se em como ganhar dinheiro fazendo o dinheiro trabalhar por você, coloque seu desejo de consumir para motivar seu gênio financeiro a investir.

$9^{\circ}$ - A necessidade de heróis, temos a necessidade de nos espelhar em alguém positivo, pessoas bem sucedidas como exemplo, porque se eles conseguiram nós também conseguiremos.

$10^{\circ}$ - Doe antes de receber, sempre que puder doe algo a alguém principalmente conhecimento. Isto é uma ação, e toda a ação tem uma reação.

Há muita gente que quer fazer, em lugar de pensar, e há gente que pensa, mas não faz. As duas formas juntas são ótimas, devemos adorar idéias e adorar agir. A idéia básica é parar de fazer o que não trás resultados. Não desistir antes de tentar e pedir dicas para alguém que já tenha conquistado aquilo que você deseja.

Quando estiver comprando faça ofertas mínimas, sem a vergonha e o medo, e quando estiver vendendo sempre peça o máximo possível. Quando algo envolve dinheiro seja profissional, esperto, queira só ganhar. Pessoas que pensam pequeno não conseguem grandes oportunidades, comece pensando grande e termine pensando maior ainda.Finalmente o autor propõe que você precisa agir antes de poder receber recompensas financeiras.

Trata-se de um bom livro, com idéias interessantes, baseadas principalmente em uma experiência pessoal real.

\section{Sobre o autor:}

(1) Aramis de Albuquerque Farias é Acadêmico de engenharia do Instituto Militar de Engenharia IME. Rio de Janeiro/RJ. E-mail: fariasaramis@ hotmail.com

\section{Como citar este artigo (Formato ISO):}

FARIAS, A.A. Resenha. Id on Line Revista de Psicologia, Fevereiro de 2011, vol.1, n.13, p.20-22. ISSN 1981-1189. 